\title{
Fabrication of Superhydrophobic Zinc Stearate Hierarchical Surfaces from Different Precursors
}

\author{
Edna Richard, C. Anandan, and S. T. Aruna \\ Surface Engineering Division, CSIR-National Aerospace Laboratories, HAL Airport Road, Bangalore, India
}

\begin{abstract}
The fabrication of zinc stearate superhydrophobic hierarchical surfaces from two precursors by a simple wet chemical route and its wettability is reported. The zinc stearate coatings were prepared from a single pot using ethanolic solutions of zinc acetate/zinc nitrate and stearic acid. The coatings were characterized by X-ray diffraction, X-ray photoelectron spectroscopy, Fourier-transform infrared spectroscopy, field emission scanning electron microscopy, water contact angle, and sliding angle measurements. The coatings obtained from zinc acetate precursor showed superhydrophobicity (WCA $>150^{\circ}$ ) even at lower precursor concentrations. The morphology of the coatings varied with the nature as well as the concentration of the precursors.
\end{abstract}

Keywords Acetate; Angle; Contact; Microstructure; Morphology; Nitrate; Precursors; Roughness; Sliding; Stearate; Superhydrophobic.

\section{INTRODUCTION}

Superhydophobicity observed in biological structures such as lotus leaf has attracted researchers due to their broad range of applications extending from self-cleaning materials to microfluidic devices [1-5]. Generally, surfaces with a water contact angle (WCA) greater than $150^{\circ}$ and sliding angle (SA) less than $10^{\circ}$ are called superhydrophobic surfaces. Water drops on such surfaces effortlessly roll off, washing away dirt completely and thus realizing the "lotus effect." This effect is attributed to the combination of micro-nano surface roughness and low surface energy which is based on the studies carried out by Neinhuis and Barthlott on the lotus leaf [6]. Accordingly, two strategies have been developed to create artificial superhydrophobic surfaces: (i) create a rough surface and modify it with a low surface energy material and (ii) roughen the surface of hydrophobic material and make it superhydrophobic. A large number of papers on superhydrophobic surfaces from metals, metal oxides, and polymers have been reported [7-12].

Zinc stearates are well-known lubricant additives that improve pigment or filler dispersion in hydrophobic plastics media [13]. Zinc stearate also finds application as an acid scavenger and processing aid in certain polyolefin applications. Zinc stearates are being used in the paint and coatings industry for pigment suspension, and also as hydrophobic agents for plasters. Recently, superhydrophobic zinc oxide surfaces have been modified with stearic acid. Zinc oxide stearate superhydrophobic

Received November 28, 2014; Accepted January 12, 2015

Address correspondence to S. T. Aruna, Surface Engineering Division, CSIR-National Aerospace Laboratories, HAL Airport Road, P.B. No. 1779, Bangalore 560017, India; E-mail: aruna_ reddy@nal.res.in

Color versions of one or more of the figures in the article can be found online at www.tandfonline.com/lmmp. surface has been fabricated by modifying solution combustion synthesized $\mathrm{ZnO}$ with stearic acid [14]. A layer of lamellar superhydrophobic zinc stearate coating on a wood surface through a wet chemical process has been reported [15]. Gurav et al. studied the static and dynamic wettability of zinc oxide nanorods modified with different concentrations of stearic acid [16].

In this article, we report the preparation of zinc stearate superhydrophobic surfaces starting from zinc precursors like zinc acetate and zinc nitrate instead of $\mathrm{ZnO}$. The effect of different concentrations of the zinc precursors on the microstructure and wettability of the surfaces has been studied.

\section{MATERIALS AND METHODS}

Zinc acetate, zinc nitrate, and stearic acid were purchased from Loba Chemie (Mumbai, India). Ammonium hydroxide and ethanol were purchased from Merck. A definite amount of zinc acetate/or zinc nitrate was dissolved in $40 \mathrm{~mL}$ ethanol followed by the addition of ammonium hydroxide to obtain $0.01,0.025,0.1,0.2$, and $0.3 \mathrm{M}$ solutions. Then, $5 \mathrm{~mL}$ of $5 \mathrm{wt} \%$ stearic acid (designated as SAc) solution in ethanol was added to the above solution to obtain the final precursor solution (designated as $\mathrm{ZnA}$ for zinc acetate and $\mathrm{ZnN}$ for zinc nitrate precursor). During the addition of ammonium hydroxide, the solution which was milky in the beginning turned clear due to the formation of zinc amino complex. The precursor solution was then heated to $70^{\circ} \mathrm{C}$ and maintained at that temperature for about $45 \mathrm{~min}$ in an open beaker. The $\mathrm{pH}$ of the precursor solution at the start of the experiment was 10 which reduced to 8 after $45 \mathrm{~min}$. At this stage, the precursor solution was uniformly spread over a cleaned glass substrate using a glass rod to obtain the coating. The as-prepared coatings were dried at ambient conditions.

Contact angle analyzer (model Phoenix 300 Plus, M/s Surface Electro Optics) was used for measuring static 
WCA of the coatings using $8 \mu \mathrm{L}$ as the drop volume. Tangent fitting mode was used in this instrument for the determination of WCA. Five measurements of WCA on the coating were taken, and the mean value has been reported. A simple in-house fabricated setup was used for measuring SA - the angle at which the drop slides was measured by means of a protractor attached to the setup. The crystalline nature of the coatings was examined by X-ray diffraction (XRD) technique using powder X-ray diffractometer (Bruker D-8 Advanced) with $\mathrm{Cu} \mathrm{K} \alpha$ radiation of wavelength $0.154 \mathrm{~nm}$. Surface morphology of the coatings was examined using field emission scanning electron microscope (FESEM, Carl Zeiss). X-ray photoelectron spectra (XPS) of the coatings were obtained using Specs, surface nanoanalysis. Fouriertransform infrared (FTIR) spectra were recorded on Bruker Alpha-P spectrometer.

\section{RESULTS AND DISCUSSION}

Figure 1 shows the XRD patterns of the powders obtained by stripping off the coatings prepared from $0.3 \mathrm{M} \mathrm{ZnA}$ and $\mathrm{ZnN}$ precursors. Five XRD peaks were detected corresponding to Bragg angles $6.53^{\circ}, 8.6^{\circ}$, $10.6^{\circ}, 19.5^{\circ}$, and $23.6^{\circ}$, respectively. All the diffraction peaks are indexed to zinc stearate, which is in accordance with the JCPDS file No. 05-0079.

XPS analysis was employed to understand the chemical composition and chemical state of the elements present on the surfaces prepared from two different precursors, i.e., $\mathrm{ZnN}$ and $\mathrm{ZnA}$ at higher concentration $(0.3 \mathrm{M})$. The broad survey scan XPS spectra of the coatings (Fig. 2) prepared from both the precursors show the presence of $\mathrm{Zn}, \mathrm{C}$, and $\mathrm{O}$. The peaks observed at binding energies of 1020.5 and $1043.4 \mathrm{eV}$ correspond to $\mathrm{Zn} 2 \mathrm{p}_{3 / 2}$ and $\mathrm{Zn} 2 \mathrm{p}_{1 / 2}$ states. The peak at $532.2 \mathrm{eV}$ confirms $\mathrm{O}-\mathrm{Zn}$ bonding state. The $\mathrm{C} 1 \mathrm{~s}$ peak at $284.0 \mathrm{eV}$ arises due to stearic acid modification [16]. From the XPS study, it is evident that irrespective of the precursors used for preparing zinc stearate surfaces, the chemical composition of the surface remains unaltered.

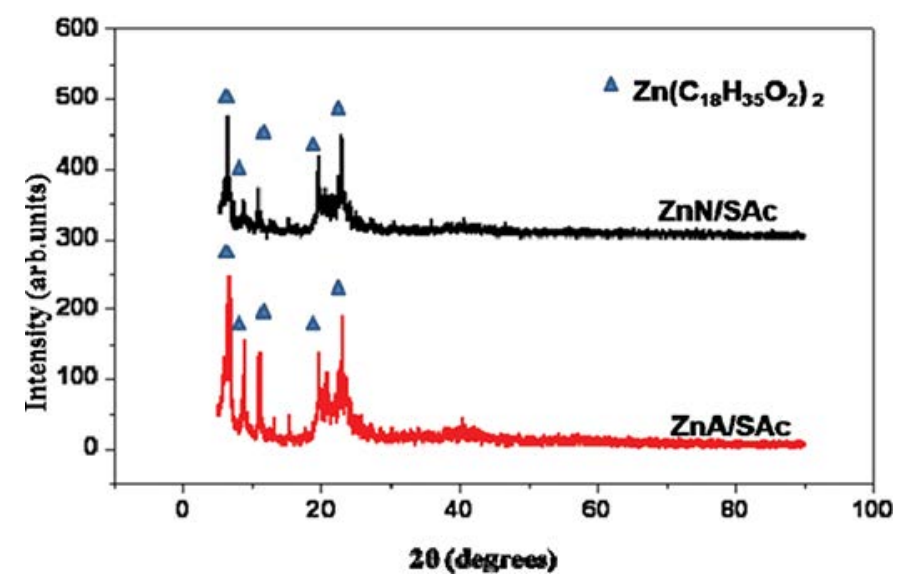

FIGURE 1.-XRD patterns of zinc stearate coatings from $0.3 \mathrm{M}$ precursor concentration.
Irrespective of the precursors used, the FTIR spectra of zinc stearate coatings were similar (Fig. 3). The bands observed at 2850 and $2920 \mathrm{~cm}^{-1}$ correspond to the symmetric and asymmetric stretching modes of zinc stearate $\left(\mathrm{C}_{36} \mathrm{H}_{70} \mathrm{O}_{4} \mathrm{Zn}\right)$. The band observed at $1541 \mathrm{~cm}^{-1}$ is attributed to asymmetric stretching of $\mathrm{COO}^{-}$. The band corresponding to unreacted stearic acid $\left(1704 \mathrm{~cm}^{-1}\right)$ was not observed. The observed bands match well with the reported literature [14].

The surface wettability of the coatings developed from $\mathrm{ZnN}$ and $\mathrm{ZnA}$ precursors was evaluated based on WCA and SA measurements (Table 1). The coatings prepared with $\mathrm{ZnA}$ and $\mathrm{ZnN}$ precursors without using stearic acid were hydrophilic with WCA of $\sim 28^{\circ}$ and $31^{\circ}$, respectively. Such hydrophilicity can be transformed to hydrophobicity by incorporating a low surface energy material like stearic acid. A smooth coating of stearic acid (from $5 \mathrm{wt} \%$ ) showed a WCA of $76^{\circ}$. The amount of stearic acid added to the precursors was optimized and used throughout the study $(5 \mathrm{~mL}, 5 \mathrm{wt} \%)$. Figure 4 shows the effect of precursor concentrations on WCA. It clearly shows that, as the concentration of $\mathrm{ZnN}$ or $\mathrm{ZnA}$ was increased, there was an increase in WCA. A higher WCA of $155^{\circ}$ was obtained for the coatings prepared from $0.3 \mathrm{M} \mathrm{ZnA}$ compared to the WCA of $150^{\circ}$ obtained from $0.3 \mathrm{M} \mathrm{ZnN}$ precursor. Therefore at higher concentrations, coatings from both the precursors exhibit superhydrophobicity. It is interesting to note that at lower precursor concentration of $0.025 \mathrm{M}$, superhydrophobic coating was obtained from $\mathrm{ZnA}$ (WCA $152^{\circ}$ ), whereas a hydrophobic coating was obtained from $\mathrm{ZnN}$ (WCA $132^{\circ}$ ) precursor. Superhydrophobicity requires a unique combination of micro-nano surface roughness and low surface energy. Even though stearic acid is a low surface energy material, it alone cannot impart superhydrophobicity. Obviously, the micro-nano surface roughness created by the precursors is also responsible for the superhydrophobicity.

The surface morphology of the coatings prepared from different precursors was observed by FESEM. Figure 5(a) shows the microstructure of the coating formed from $0.3 \mathrm{M} \mathrm{ZnA}$, and it was essentially a uniform array of dense microparticles akin to flowers having closed petals. The diameter of the flowers formed was in the range of $5-10 \mu \mathrm{m}$. The inset of Fig. 5(a) shows a magnified image of one such flower. The petal of the flower resembled hexagonal flake with length and diameter almost equal to $1 \mu \mathrm{m}$. It has also been reported in the literature that the morphology of the zinc oxide crystals formed from chemical bath was affected by the reaction temperature, and flower-like morphology was obtained at a lower temperature [17]. Figure 5(b) represents the microstructure of the coating prepared from $0.3 \mathrm{M}$ $\mathrm{ZnN}$ solution, which shows a random mixture of irregular flower and leaf-like structures.

Since the coatings prepared from zinc acetate were superhydrophobic even with lower precursor concentration $(0.025 \mathrm{M})$, the surface morphology of these coatings was analyzed to account for the WCAs. Figure 6(a) shows the surface morphology of the coating obtained from zinc acetate at lower precursor concentration. 


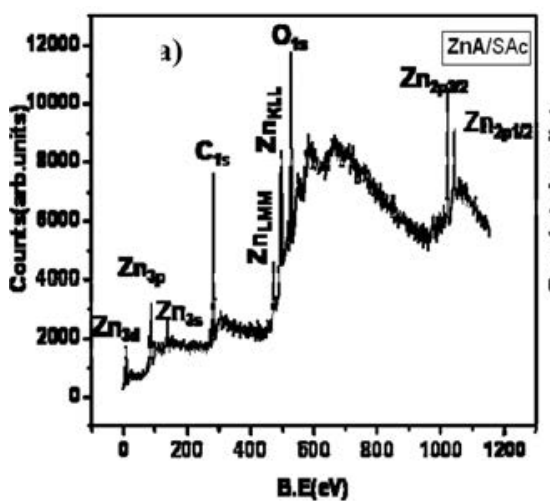

(a)

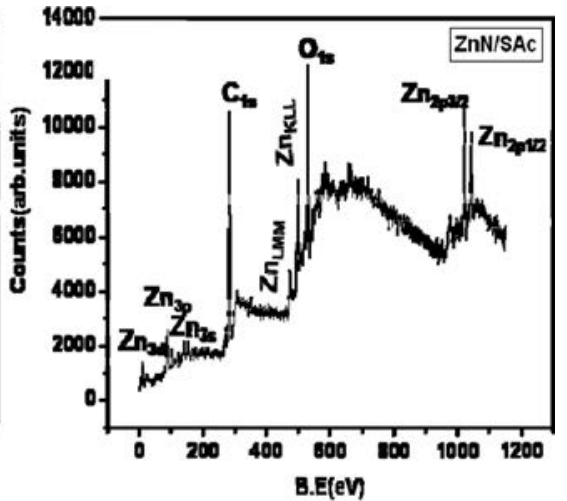

(b)

FIGURE 2.-XPS spectra of coating prepared from (a) $0.3 \mathrm{M} \mathrm{ZnA}$ and (b) $0.3 \mathrm{M} \mathrm{ZnN}$.

Flower-like structures with diameter ranging from 5 to $25 \mu \mathrm{m}$ were formed. Each flower consisted of a number of petals, tapering at the end with diameter less than $1 \mu \mathrm{m}$ and length almost $3 \mu \mathrm{m}$. The coating exhibited a WCA of $152^{\circ}$ and a SA less than $2^{\circ}$. Figure $6(\mathrm{~b})$ shows the FESEM images of the coatings prepared from $0.025 \mathrm{M} \mathrm{ZnN}$ precursor. The WCA of the coating prepared from $\mathrm{ZnN}$ precursor was $132^{\circ}$. The flowers in this case were different from the ones formed from zinc acetate precursor. The diameter of each flower was about $10 \mu \mathrm{m}$. The numbers of individual flowers were less and the space between each flower was filled with petal-like structures of diameter $2 \mu \mathrm{m}$, and hence the WCA was less compared to the ones prepared from zinc acetate. To examine the role of stearic acid in influencing the morphology of zinc stearate flowers, two control samples were prepared from zinc acetate and zinc nitrate precursors without stearic acid. Figure 7(a) illustrates FESEM images of the coatings prepared from $0.025 \mathrm{M} \mathrm{ZnN}$ and 7(b) shows the images of coatings prepared from $0.025 \mathrm{M}$ $\mathrm{ZnA}$ solution without stearic acid. Micron-sized flowers were absent in both the coatings and instead oblate

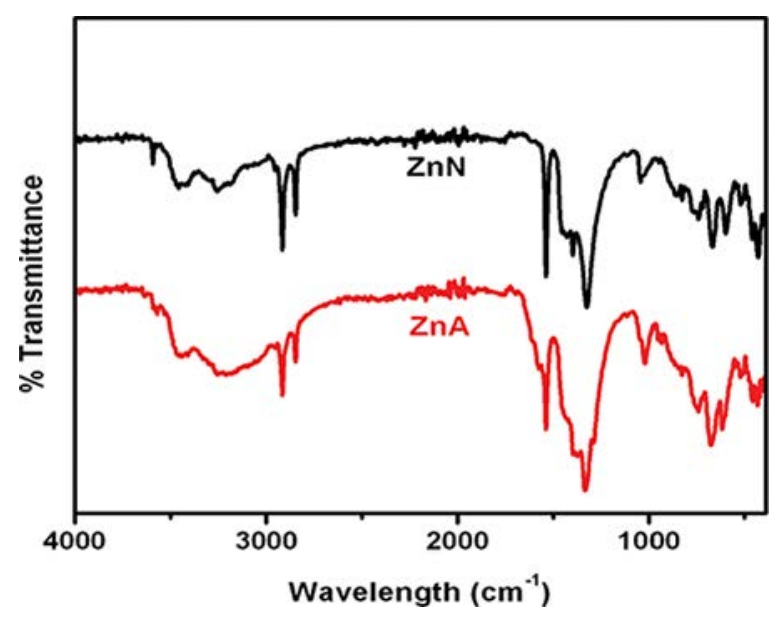

FIGURE 3.-FTIR spectra of superhydrophobic zinc stearate coatings from $\mathrm{ZnA}$ and $\mathrm{ZnN}$ precursors. structures with diameter less than $10 \mu \mathrm{m}$ were formed in the coating prepared from zinc acetate solution (inset 7(b)). The formation of zinc oxide oblate structures from an alkaline zinc acetate solution has been previously reported by Sun et al. [18]. In the absence of stearic acid,

TABLE 1.-Contact angle, sliding angle, and drop profile of the zinc stearates coatings.

\begin{tabular}{lcc}
\hline Coatings with & WCA & Sliding angle \\
\hline 1) Stearic acid alone & $36^{\circ}$ & $>90^{\circ}$ \\
2) $\mathrm{ZnN}$ alone & & \\
3) $\mathrm{ZnA}$ alone & $28^{\circ}$ & $>90^{\circ}$ \\
4) $0.3 \mathrm{M} \mathrm{ZnN} / \mathrm{SAc}$ & $150^{\circ}$ & \\
5) $0.3 \mathrm{M} \mathrm{ZnA} / \mathrm{SAc}$ & & \\
\end{tabular}




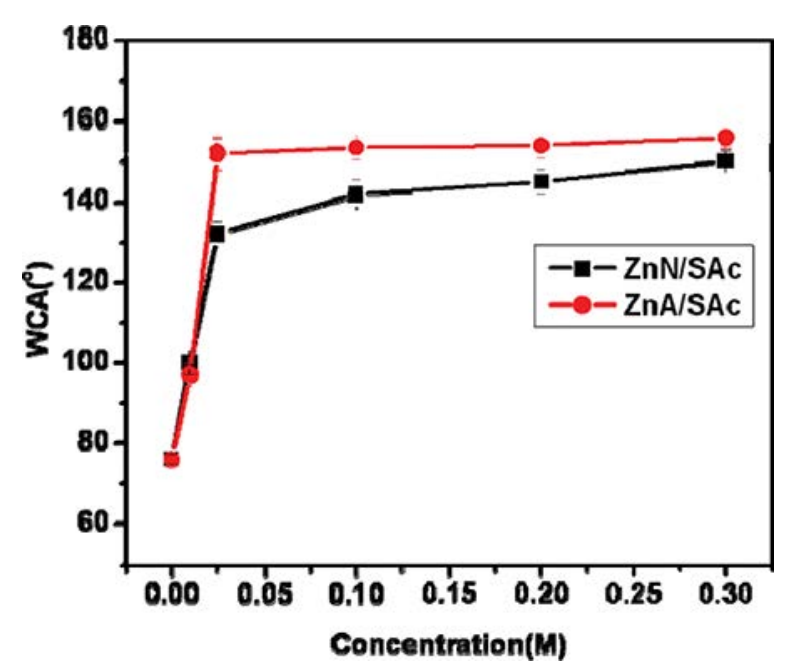

FIGURE 4.-Effect of precursor concentration on WCA for the coatings obtained from $\mathrm{ZnA}$ and $\mathrm{ZnN}$.

the coatings prepared from both the precursors were hydrophilic with WCA of $28^{\circ}$ and $31^{\circ}$, respectively, for zinc acetate and zinc nitrate precursors. Thus, apart from imparting a low surface energy to the coating, stearic acid may be influencing the morphology of zinc stearate flowers to some extent.

A probable reaction mechanism for the formation of zinc stearate flowers is proposed based on the observations made during the preparation. It was observed that by the addition of $\mathrm{NH}_{4} \mathrm{OH}$ to an ethanolic solution of $\mathrm{Zn}\left(\mathrm{CH}_{3} \mathrm{COO}\right)_{2} \cdot 2 \mathrm{H}_{2} \mathrm{O}$ a curd-like white precipitate was formed which dissolved in excess of $\mathrm{NH}_{4} \mathrm{OH}$. The precipitate was due to the formation of $\mathrm{Zn}(\mathrm{OH})_{2}$ according to the reaction:

$$
\begin{aligned}
\mathrm{Zn}\left(\mathrm{CH}_{3} \mathrm{COO}\right)_{2}+ & 2 \mathrm{NH}_{4} \mathrm{OH} \rightarrow \mathrm{Zn}(\mathrm{OH})_{2} \\
& +2 \mathrm{CH}_{3} \mathrm{COONH}_{4}
\end{aligned}
$$

Addition of excess $\mathrm{NH}_{4} \mathrm{OH}$ to the solution facilitates the dissolution of $\mathrm{Zn}(\mathrm{OH})_{2}$, resulting in the formation of tetra ammonium zinc hydroxide at $\mathrm{pH} 10$

$$
\begin{aligned}
& \mathrm{Zn}(\mathrm{OH})_{2}+4 \mathrm{NH}_{4} \mathrm{OH} \rightarrow \mathrm{Zn}\left(\mathrm{NH}_{3}\right)_{4}(\mathrm{OH})_{2}+4 \mathrm{H}_{2} \mathrm{O} \\
& \mathrm{Zn}\left(\mathrm{NH}_{3}\right)_{4}(\mathrm{OH})_{2} \rightarrow \mathrm{Zn}\left(\mathrm{NH}_{3}\right)_{4}^{+2}+2 \mathrm{OH}^{-}
\end{aligned}
$$

Since the reaction is taking place in an open beaker, excess ammonia can escape resulting in the formation of zinc oxide. $\mathrm{Li}$ et al. have demonstrated that $\mathrm{ZnO}$ formation from basic solutions of zinc acetate by forced hydrolysis is facilitated by the use of open baths [19]. Thus, $\mathrm{ZnO}$ particles are formed by forced hydrolysis of $\mathrm{Zn}\left(\mathrm{NH}_{3}\right)_{4}^{+2}$ in the open bath prior to the reaction with stearic acid as depicted by the reaction.

$$
\mathrm{Zn}\left(\mathrm{NH}_{3}\right)_{4}^{+2}+2 \mathrm{OH}^{-} \rightarrow \mathrm{ZnO}+4 \mathrm{NH}_{3}+2 \mathrm{H}_{2} \mathrm{O}
$$

The so-formed $\mathrm{ZnO}$ crystals in their hexagonal form have both polar (001) and nonpolar faces (101) parallel to the c-axis. Dipoles of positively charged $\mathrm{Zn}^{2+}$ and negatively charged $\mathrm{O}^{2-}$ are present on the polar faces. The polar face is thermodynamically less stable than those of other nonpolar faces and tends to grow along c-axis [20]. However, in the present study, since there are different kinds of ions present in the reaction system (i.e., acetate/stearate and $\mathrm{OH}^{-}$in case of zinc acetate precursor solution and nitrate/stearate and $\mathrm{OH}^{-}$in case of zinc nitrate precursor solution), it is necessary to explore the functions of these groups in the development of the flower-like morphology. It is reported that excess of $\mathrm{CH}_{3} \mathrm{COO}^{-}-, \mathrm{NO}_{3}^{-}$, and $\mathrm{OH}^{-}$ions limit the growth along the c-axis and results in the formation of plate like petals $[21,22]$. The positively charged $\mathrm{Zn}^{2+}$ of zinc oxide reacts with stearate ion to form zinc stearate. The formation of flower-like particles can be attributed to twinning and fourling growth [23].
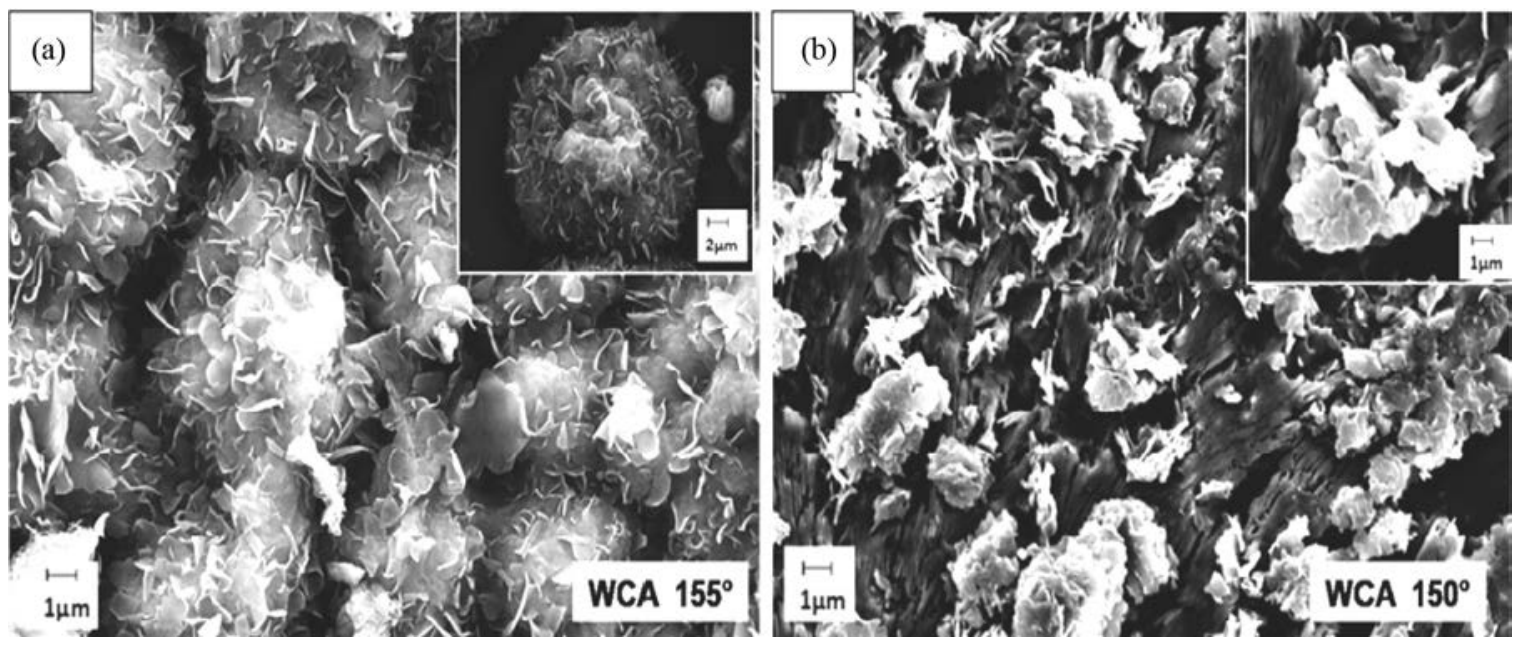

FIGURE 5.-FESEM images of zinc stearate flowers prepared from (a) $0.3 \mathrm{M} \mathrm{ZnA}$, (b) $0.3 \mathrm{M} \mathrm{ZnN}$ at magnification $8 \mathrm{~K} \times$ (inset $25 \mathrm{~K} \times$ ). 

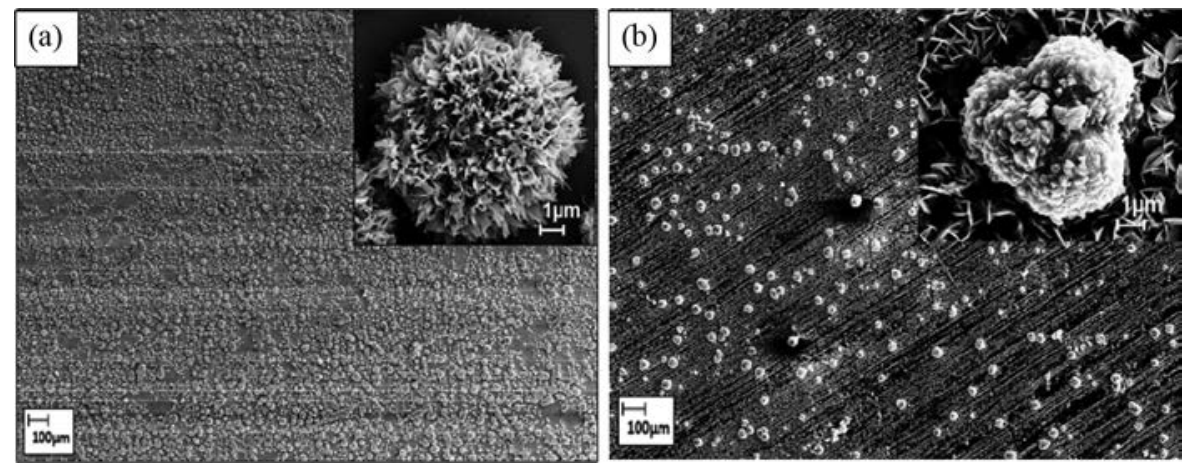

FIGURE 6. - FESEM images of zinc stearate flowers prepared from (a) $0.025 \mathrm{M} \mathrm{ZnA}$ and (b) $0.025 \mathrm{M} \mathrm{ZnN}$ at magnification $350 \times$ (inset $11 \mathrm{~K} \times$ ).

Wenzel and Cassie Baxter model has been used to explain the influence of surface roughness on wettability. According to Wenzel model, the liquid drop completely penetrates the surface and wets the surface. According to Casssie Baxter model, the water drop sits on the hills and valleys of the surfaces without wetting it. A superhydrophobic behavior is generally explained in terms of the Cassie-Baxter model [24], according to which,

$\cos \theta_{\mathrm{c}}=f_{1}\left(\cos \theta_{\mathrm{e}}+1\right)-1$

where $\theta_{\mathrm{c}}$ is apparent WCA and $\theta_{\mathrm{e}}$ is the equilibrium WCA. $f_{1}$ is the surface area fraction of the solid.

The coatings prepared from $0.3 \mathrm{M}$ ethanolic precursor solutions ( $\mathrm{ZnA}$ and $\mathrm{ZnN}$ ) with stearic acid were superhydrophobic and are in Cassie's state. The surface area fraction of the solid $f_{1}$ of the coatings can be calculated using the following equation.

$f_{1}=\frac{\left(\cos \theta_{\mathrm{c}}+1\right)}{\left(\cos \theta_{\mathrm{e}}+1\right)}$

The flat smooth coatings of stearic acid obtained showed a WCA $\left(\theta_{\mathrm{e}}\right)$ of $76^{\circ}$. By substituting the values of $\theta_{\mathrm{e}}$ and $\theta_{\mathrm{c}}$ (observed WCA) in Eq. (6), $f_{1}$ was calculated for the coatings obtained from different precursors at higher $(0.3 \mathrm{M})$ and lower $(0.025 \mathrm{M})$ precursor concentration. The surface area fraction of air trapped between the zinc stearate flowers and the water droplet $\left(f_{2}\right)$ can also be calculated as $f_{2}=1-f_{1}$. The lowest $f_{1}$ value of 0.0754 and 0.0942 was obtained for the zinc stearate coatings formed from $0.3 \mathrm{M}$ and $0.025 \mathrm{M}$ zinc acetate precursor solution having flower-like morphology. The corresponding surface area fraction of air trapped under the water drop in contact with flower-like structure for $0.3 \mathrm{M}$ and $0.025 \mathrm{M} \mathrm{ZnN}\left(f_{2}\right)$ was 0.1078 and 0.2663 , respectively. It has to be noted that a decrease in $f_{1}$ indicates an increase in surface roughness. The $f_{1}$ value was high $(0.2663)$ for the microstructures formed from the zinc nitrate precursor at lower concentration $(0.025 \mathrm{M})$. This may be attributed to the presence of less number of flower-like structures formed with zinc nitrate precursor. Thus, a water drop on the zinc stearate surface formed from zinc acetate precursor only contacts the tips of the clusters and flower-like structures, resulting in a large water-air interface. Such composite surface prevents water droplets from penetrating into the cavities, thus leading to superhydrophobicity.

\section{Conclusions}

- Zinc stearate superhydrophobic hierarchical surfaces were prepared from ethanolic solution of zinc acetate/zinc nitrate by the addition of stearic acid.

- The coatings obtained from zinc acetate precursor showed superhydrophobicity with WCA $>150^{\circ}$ even at lower concentration of zinc acetate precursor.
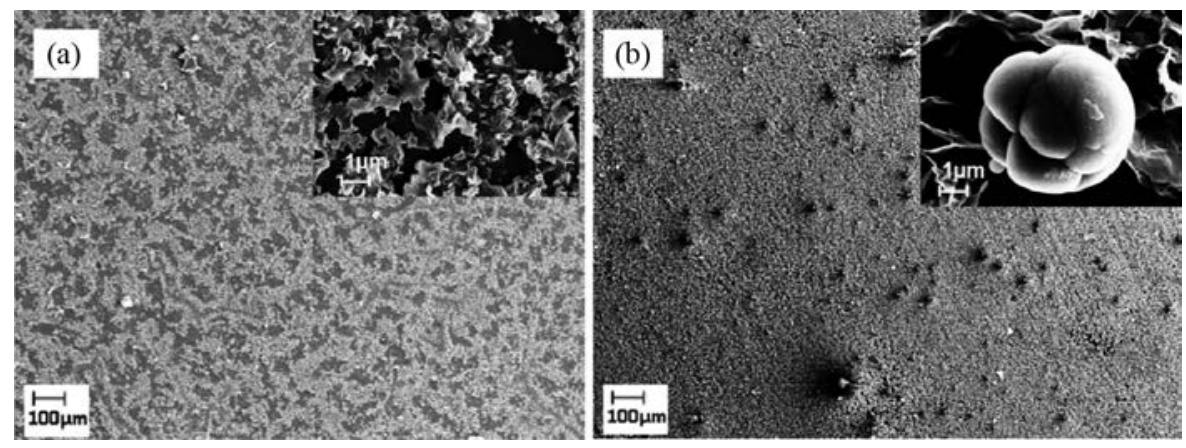

Figure 7.-FESEM images of coatings prepared from (a) $0.025 \mathrm{M} \mathrm{ZnN}$ at magnification $350 \times$ (inset $11 \mathrm{~K} \times$ ) and (b) $0.025 \mathrm{M} \mathrm{ZnA}$ at magnification $350 \times($ inset $19 \mathrm{KX})$ without stearic acid. 
- XRD, XPS, and FTIR studies confirmed the formation of zinc stearate.

- The hydrophobicity of the films can be tuned and controlled by the nature and concentration of precursors.

- The surface morphology of the coatings formed from zinc acetate and zinc nitrate precursors were different as evident from FESEM.

- The surface area fraction of air trapped inside the micronano surface was evaluated and found to be higher for the surfaces obtained from zinc acetate precursor $\left(f_{2}\right.$ was 0.948$)$.

- The superhydrophobicity was achieved by the synergistic effect of surface roughness and low surface energy of stearic acid.

- This study clearly shows that zinc acetate is a preferred precursor for the fabrication of superhydrophobic surfaces.

- The present work not only demonstrated a facile route for the preparation of zinc stearate hierarchical micro/ nanostructures, but also provides a very easy method to fabricate superhydrophobic coatings in less time.

\section{ACKNOWLEDGMENTS}

We thank Mr Siju for FESEM studies, Mr G.Srinivas and Dr RPS Chakradhar for XRD, and Dr Parthasarathi Bera for XPS measurements. The authors thank Mrs. Lakshmi for the FTIR studies. One of the authors Edna Richard acknowledges CSIR-UGC for the fellowship and the Chairman, Mangalore, university for the encouragement. We are grateful to Director, CSIR-NAL, Bangalore, for supporting this work.

\section{REFERENCES}

1. Huang, Y.F.; Huang, C.; Zhong, Y.L.; Yi, S.P. Preparing superhydrophobic surfaces with very low contact angle hysteresis. Surface Engineering 2013, 29, 633-636.

2. Zhang, H.; Lamb, R.N. Superhydrophobic treatment for textiles via engineering nanotextured silica/polysiloxane hybrid material onto fibres. Surface Engineering 2009, 1, 21-24.

3. Wang, R.G.; Kaneko, J. Hydrophobicity and corrosion resistance of steels coated with PFDS film. Surface Engineering 2013, 29, 255-263.

4. Xu, Q.F.; Wang, J.N.; Sanderson, K.D. Organic-inorganic composite nanocoatings with superhydrophobicity, good transparency, and thermal stability. ACS Nano 2010, 4, 2201-2209.

5. Ma, M.R.; Hill, M. Superhydrophobic surfaces. Current Opinion in Colloid \& Interface Science 2006, 11, 193-202.

6. Barthlott, W.; Neinhuis, C. Characterization and distribution of water-repellent, self-cleaning plant surfaces. Annals of Botany 1997, 79, 667-677.

7. Badre, C.; Mayaffre, A.; Letellier, P.; Turmine, M. Modification of the wettability of a polymeric substrate by $\mathrm{pH}$ effect: determination of the surface acid dissociation constant by contact angle measurements. Langmuir 2006, $22,8424-8430$.
8. Jun, Wu.; Jing Chen.; Jun Xia.; Wei Lei.; Bao-ping Wang. A brief review on bioinspired $\mathrm{ZnO}$ superhydrophobic surfaces: theory, synthesis, and applications. Advances in Materials Science and Engineering 2013, Article ID 232681.

9. Sanjay, S.L.; Annaso, B.G.; Chavan, S.M.; Rajiv, S.V. Recent progress in preparation of superhydrophobic surfaces: A review. Journal of Surface Engineered Materials and Advanced Technology 2012, 2, 76-94.

10. Wang, S.; Feng, L.; Jiang, L. One-step solution-immersion process for the fabrication of stable bionic superhydrophobic surfaces. Advanced Materials 2006, 18, 767-770.

11. Huang, Y.; Sarkar, D.K.; -Grant Chen, X. A one-step process to engineer superhydrophobic copper surfaces. Materials Letters 2010, 64, 2722-2724.

12. Li, J.; Wan, H.; Ye, Y.; Zhou, H.; Chen, J. One-step process for the fabrication of superhydrophobic surfaces with easy repairability. Applied Surface Science 2012, 258, 3115-3118.

13. Capelle, H.A.; Britcher, L.G.; Morris, G.E. Sodium stearate adsorption onto titania pigment. Journal of Colloid Interface Science 2003, 268, 293-300.

14. Chakradhar, R.P.S.; Kumar, V.D. Water-repellent coatings prepared by modification of $\mathrm{ZnO}$ nanoparticles. Spectrochimica Acta A 2012, 94, 352-356.

15. Wang, S.; Shi, J.; Liu, C.; Xie, C.; Wang, C. Fabrication of a superhydrophobic surface on a wood substrate. Applied Surface Science 2011, 257, 9362-9365.

16. Gurav, A.B.; Latthe, S.S.; Vhatkar, R.S.; Lee, J.-G.; Kim, D.-Y.; Park, J.-J.; Yoon, S.S. Superhydrophobic surface decorated with vertical $\mathrm{ZnO}$ nanorods modified by stearic acid. Ceramic International 2014, 40, 7151-7160.

17. Wang, Z.; Qian, X.-F.; Yin, J.; Zhu, Z.-K. Large-scale fabrication of tower-like, flower-like, and tube-like $\mathrm{ZnO}$ arrays by a simple chemical solution route. Langmuir 2004, 20, 3441-3448.

18. Sun, L.; Shao, R.; Chen, Z.; Tang, L.; Dai, Y.; Ding, J. Alkali-dependent synthesis of flower-like $\mathrm{ZnO}$ structures with enhanced photocatalytic activity via a facile hydrothermal method. Applied Surface Science 2012, 258, 5455-5461.

19. Li, W.J.; Shi, E.W.; Zhong, W.Z.; Yin, Z.W. Growth mechanism and growth habit of oxide crystals. Journal of Crystal Growth 1999, 203, 186-196.

20. Govender, K.; Boyle, D.S.; Kenway, P.B.; Brien, P.O. Understanding the factors that govern the deposition and morphology of thin films of $\mathrm{ZnO}$ from aqueous solution. Journal of Materials Chemistry 2004, 14, 2575-2591.

21. Zhang, D.; Sun, L.; Zhang, J. Hierarchical construction of $\mathrm{ZnO}$ architectures promoted by heterogeneous nucleation. Crystal Growth and Design 2008, 8, 3609-3615.

22. Yu, Q.; Yu, C.; Yang, H.; Fu, W.; Chang, L.; Xu, J.; Wei, R.; Li, H.; Zhu, H.; Li, M.; Zou, G. Growth of dumbbell-like $\mathrm{ZnO}$ microcrystals under mild conditions and their photoluminescence properties. Inorganic Chemistry 2007, 46, 6204-6210.

23. Gao, X.; Li, X.; Yu, W. Flowerlike Zno nanostructures via hexamethylenetetramine-assisted thermolysis of zincethylenediamine complex. Journal of Physical Chemistry B 2005, 109, 1155-1161.

24. Cassie, A.B.D.; Baxter, S. Wettability of porous surfaces. Transactions of the Faraday Society 1944, 40, 546-551. 